\title{
Editorial: Children's Health from Global Determinants to Local Consequences: The Indian Perspective
}

\author{
Dario Gregori ${ }^{1} \cdot$ Achal Gulati $^{2} \cdot$ Ileana Baldi ${ }^{1}$ \\ Received: 16 October 2018 / Accepted: 16 November 2018 /Published online: 9 January 2019 \\ (C) Dr. K C Chaudhuri Foundation 2019
}

Children's health must be set as a priority all over the world $[1,2]$, in particular now-a-days, when new challenges are emerging at a higher level of complexity. Such problems go beyond traditional clinical settings, and they include, in a non-exhaustive list, increase of obesity rate in children, increase in mortality and burden of injuries, higher prevalence of mental health-related issues, and difficulties in transition to adolescence. This requires the adoption of a holistic, integrated view among research clinics and prevention and public health interventions to effectively tackle the issue. In particular for research, cross-contamination at international level is mandatory to elicitate common pattern and to identify peculiarities at the geographical or socio-economic level [3].

This Supplement is adopting this perspective by putting together several research contributions from Italy, India, and Malaysia, building on the previous work on non-traditional risk factors for obesity in children [4]. The work has been developed under the umbrella of the Executive Programme of Scientific and Technological Cooperation between the Italian Republic and the Republic of India for years 20122014, under the joint support of the Italian Ministry of Foreign Affairs, and the Indian Ministry of Science \& Technology [5].

Continuing along the same lines, the aim of this ItalianIndia research cooperation, is to look at children to provide those data which we believe are needed for a modern,

Dario Gregori

dario.gregori@unipd.it

1 Unit of Biostatistics, Epidemiology and Public Health, Department of Cardiac, Thoracic, Vascular Sciences and Public Health, University of Padua, Padua, Italy

2 Department of Otorhinolaryngology and Head and Neck Surgery (ENT), Maulana Azad Medical College and Associated Lok Nayak Hospital, New Delhi, India evidence-based approach to foster their health in a converging perspective among several medical specialties.

In this Special Issue, the first Italian study addresses a very current topic, the migratory flow directed towards the Italian territory, that poses new challenges about the guarantee of fundamental human rights, especially towards little children. In this context, Bardin et al. [6] investigate the role of maternal citizenship on the risk of avoidable hospitalization of their children.

In the second study, the focus is on the usage of pediatric trials with at least one enrolling site in India [7]. In fact, clinical research in pediatric population is complex and can be challenging because of this potentially fragile population together with safety concerns and stringent ethical requirements.

In India again, Lorenzoni et al. explore the association between obstructive sleep apnea and obesity-related metabolic outcomes in obese children, through an observational, crosssectional, single-center study [8].

Foreign body aspiration in children is still a serious problem that can lead to several complications, including death. The study conducted by Gendeh et al. is the first retrospective review of publications about foreign body aspiration in various healthcare centres in Malaysia in the last $45 \mathrm{y}$ [9].

Last two studies address another delicate topic: the transition from childhood to adolescence. In the first one, Bianchin et al. conducted a population-based study on school-aged girls aimed to evaluate headache pain pattern during the menstrual cycle, and verify its relationships with physical, psychosocial and life-style factors [10]. In the second one, a multicenter cross-sectional study on a large sample of Italian girls, De Sanctis et al. explore the independent role of age at menarche on menstrual abnormalities among adolescents [11].

We hope that data and results, as well a methodological developments will help in a better understanding of the most recent challenges in children health in both countries. Finally, we gratefully acknowledge the help and continuous support of the Editor Emeritus of the Indian Journal of Pediatrics, Prof. Verma. 
Publisher's Note Springer Nature remains neutral with regard to jurisdictional claims in published maps and institutional affiliations.

\section{References}

1. Ham C. Priority setting in health care: learning from international experience. Health Policy. 1997;42:49-66.

2. Beaglehole R, Bonita R, Horton R, et al. Priority actions for the non-communicable disease crisis. Lancet. 2011;377:1438-47.

3. Su Y, Long C, Yu Q, Zhang J, Wu D, Duan Z. Global scientific collaboration in COPD research. Int J Chron Obstruct Pulmon Dis. 2017;12:215-25.

4. Gregori D, Gulati A, Paramesh H, Paramesh EC, Kameswaran M, Baldi I. Children obesity from global determinants to local consequences: the Indian perspective. Indian J Pediatr. 2014;81:2-4.

5. Mancini D. Non-traditional factors in childhood obesity: the ItalyIndia joint research Programme 2012-2014. Indian J Pediatr. 2014;81:1

6. Bardin A, Zuanna TD, Favarato S, et al. The role of maternal citizenship on pediatric avoidable hospitalization: a birth cohort study in north-East Italy. Indian J Pediatr. 2018. https://doi.org/10.1007/ s12098-018-2826-6.

7. Lorenzoni G, Comoretto RI, Ruffolo M, Azzolina D, Baldi I. Pediatric trials run in India: an analysis of Clinicaltrials.gov 20062015. Indian J Pediatr. 2018. https://doi.org/10.1007/s12098-0182825-7.

8. Lorenzoni G, Azzolina D, Sethi G, et al. Identifying pathways mediating obstructive sleep apnea and obesity in Indian children. Indian J Pediatr. 2018. https://doi.org/10. 1007/s12098-018-2828-4.

9. Gendeh BS, Gendeh HS, Purnima S, Comoretto RI, Gregori D, Gulati A. Inhaled foreign body impaction: a review of literature in Malaysian children. Indian J Pediatr. 2018. https://doi.org/10.1007/ s12098-018-2824-8.

10. Bianchin L, Bozzola M, Battistella Pier A, et al. Menstrual cycle and headache in teenagers. Indian J Pediatr. 2018. https://doi.org/ 10.1007/s12098-018-2829-3.

11. Sanctis De V, Rigon F, Bernasconi S, et al. Age at menarche and menstrual abnormalities in adolescence: Does it matter? The evidence from a large survey among Italian secondary schoolgirls. Indian J Pediatr. 2018. https://doi.org/10.1007/s12098-018-2822-x. 